\title{
Restructuring Hungarian Physics
}

Hungarian universities in the post-war era traditionally educated undergraduates according to the Russian model of a five year diploma. The number of diploma students graduating each year has remained fairly constant (roughly 100, representing a relatively low percentage of the country's population of 10 million) and corresponds to the domestic demand for this type of physicist.

About half of the students taking physics as the main diploma subject are taught at approximately equally sized institutes of physics at Eötvös University and at the Technical University, Budapest. The remainder study at universities elsewhere. Physics is also taught with mathematics to a larger number (to roughly 120 diploma students in each year at Eötvös University as opposed to about 25 for physics) and to a limited extent with chemistry. A few hundred students receive basic physics courses at the Semmelweis Medical University, Budapest, and many trainee teachers (some $\mathbf{3 0 0}$ at Eötvös University alone) are given courses in physics.

The hours spent by diploma students in lectures and practicals have been high by European levels (about 36 hours per week in 1988 and even higher in the 1950's). Theoretical aspects have always been emphasized and this is reflected in the number of theoreticians holding academic posts (about one-third of the professorial staff of 35 at Eötvös University's Institute of Physics).

The emphasis on high academic standards and rigorous theoretical training which has produced an amazing number of world-renowned physicists is rooted in the diploma intake. Indeed, Hungary's overall science education system is widely acknowledged as one of her major strengths. There are usually two candidates for each of Eötvös University's places in the Physics Institute as a result of rigorous selection at the gymnasia, whose teachers between the wars played a determining rôle in the development of physics in the universities. The demand for places in physics is holding up without decreasing entry standards. Physics students have consistently ranked at the top of the average entry score for entrance to Eötvös University with 118 points out of 120 . Entrance is based on a 50/50 split between marks in a university entrance exam (which is to be retained unlike in most European countries) and the maturité taken at the end of 12 years of schooling.

\section{Undergraduate Education}

Significant modifications to the undergraduate physics programme have been made. In the case of Eötvös University, changes to the computer sciences curriculum have been copied by offering a three year "bachelors" course for which a formal degree may possibly be awarded by the University Council, a completely new body reflecting the University's increased independence. This is followed by a more specialized two-year course that includes a larger amount of time for independent study and a significant reduction, to 30 hours each week, for courses and practicals. The changes will discourage students from following a rigid, closed training with an emphasis on reproducing syllabus material.

Another objective is to increase undergraduate numbers (from 50 to perhaps 80 in physics at Eötvös University) with maybe one-half staying on for the last two years. The concern here is, of course, to match education to job opportunities. The diploma output has traditionally been low to meet the country's limited demand for highly trained physicists. The thought is that physicists graduating after three years will, like computer scientists, find positions relatively easily in the Technical University and in industry.

The proportion of academic staff at the assistant professor level below the associate (docents) grade is relatively small (for example, Eötvös University's Physics Institute has six assistants on the aca-

is not being discussed in detail at present in spite of the potential for some rationalization to rectify the inherited system of fragmented and specialized institutions - both at the university level and within the numerous pedagogical institutes, intermediate between the gymnasia and universities, with maybe 25000 students. It has been planned for some time to move the Eötvös University Physics Institute to a new campus close to the Technical University, with perhaps some reorganizing, but this probably depends on the outcome of Budapest's bid to host the 1996 World Exhibition which would need new facilities and buildings.

\section{Graduate Training}

Historically, the Institutes of the Hungarian Academy of Sciences carried out the universities' natural functions in basic research so graduate students lacked equipment and participated in small groups below critical mass. The Institutes, on the other hand, were often overdimensioned for the country and involved in glamorous but essentially commercial ventures for production (e.g. the mothballed microelectronics facility at MFKI - the Research Institute for Technical Physics, a nuclear centre with an expensive waste disposal problem, etc.). At one stage roughly one-half the Academy's budget was devoted to such ventures that largely
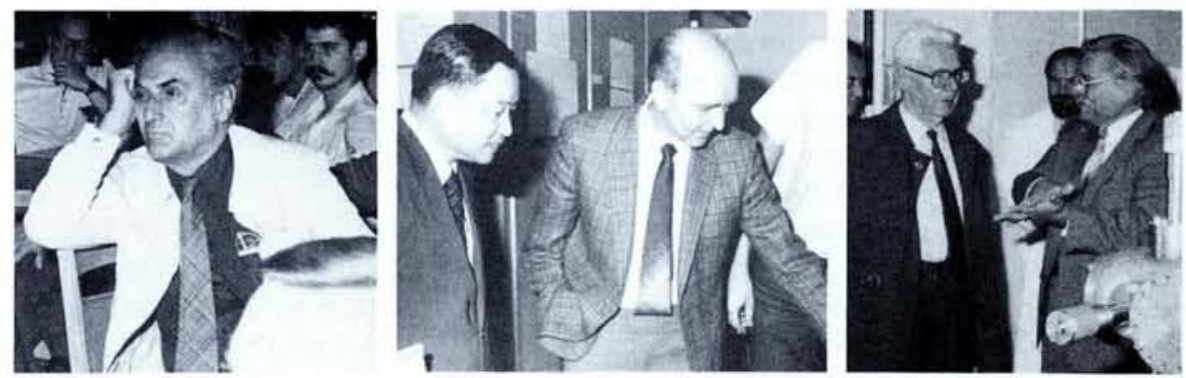

Left) Prof. D. Kosári (on the left), Chairman of the Hungarian Academy of Sciences, and Professor Lovás, Director of the Central Research Institute for Physics (KFKI). Right) Prof. N. Kroo, Director of the KFKI's Institute of Solid State Research, demonstrating equipment to a visitor from China.

demic staff). However, with low student/teacher ratios it is difficult to consider much expansion within the existing budget, even if student numbers are increased. Moreover, enthusiastic, highly qualified young academics may not continue to be attracted and motivated to keep doing good work by the promise of research opportunities but a poor salary. Salaries have been increased recently, but from a low level and inflation is serious. Nonetheless, easier and improved communications and interchange will help improve the objective evaluation of research work in making promotions. The true merit of a piece of scientific work could often not be readily evaluated if it was performed outside Hungary, especially in industrially related research.

Reorganizing the teaching of physics within the three main centres in Budapest responded to COMECON trade restrictions, the needs of a centrally planned economy with strategic sectors and an import substitution policy. The Institutes with their new philosophy of research for industry are seeking other sources of income and economies: government funding now usually covers $30 \%$ of the budget with the remainder divided between research contracts and government grants for which bids are made.

The separation of research from higher education is widely seen as a big mistake but any correction must not be too hasty. The Institutes represent vital sources of expertise and experimental facilities which should not be entirely dismantled. Professor Kroo, Director of the Institute of Solid State Research (part of the Hungarian Academy of Sciences Central Research Institute for Physics - the KFKI) envisa- 
ges that the amount of institute research will be halved and university research doubled. More institute scientists are teaching (one-third of his Institute's research staff now lecture regularly in universities) and the Solid State Institute's facilities are used by students.

It is also hoped to change graduate training by creating institutions akin to graduate schools to bridge the university institute gap. The University of Debrecen and the nearby Institute of Nuclear Physics led the way with a common unit devoted to providing teaching and research facilities for graduates in nuclear physics (Professor Lovás, the KFKI's Director-General, holds a chair of theoretical physics in the University). Meanwhile, the Institute of Solid State Research, the Eötvos, Medical and Technical Universities in Budapest and universities in Szeged and Tilich have agreed to combine efforts in graduate and postgraduate education and research by forming a loose confederation of the interested facilities and professorial chairs (the last signature of the letter of intent was received last month). Called the Athenaeum, the aim is to start operation in 1992, initially in the fields of material and solid state physics and in quantum electronics. Professor Kroo believes that eventually maybe as many as $300-400$ graduates and postgraduates would be involved so the initiative could become an important element of a restructured physics community.

The Athenaeum hopes that the pooling of resources and adopting a united approach to funding agencies will allow research facilities to be brought to modern standards by improving the existing laboratory infrastructure and equipment and by installing computer links.

Ambitious plans to make a significant impact on a countries education programme naturally call for important funding. Hungary was one of the first countries to submit proposals for restructuring to the European Community's PHARE Programme (with a budget of 800 MECU for $1990 / 1$ with no a priori splitting) which forms the basis of the EC's activities in favour of central Europe. Proposals are made through national offices on the basis of a Directive Plan submitted by each country. The PHARE Committee composed of representatives of the donors (the EC, the USA and Japan) meets every two months to agree proposals, and project implementation varies according to the requirements. Hungary included science and research in its 1990/1 Directive Plan and some of the proposed restructuring required by PHARE has already taken place (increasing student numbers, introducing additional freedom of choice in course selection and the new two-level undergraduate programme).
The Athenaeum initiative clearly represents a significant element in this restructuring by reconfiguring resources, so it is seeking some $1 \mathrm{MECU}$ for infrastructure development and 1-2 KECU for invited students, professors and researchers through a PHARE proposal submitted by the Hungarian Ministry of Industrial Development (MID). Domestic funding sources are also sought (from the Minister of Education and from OTKE, the National Organization for Scientific Research). The MID and OTKE are already heavily involved in supporting science as they, together with direct government funding, cover a major part of the budget of the Academy of Sciences and its Institutes, which are still effectively managed by the Academy, although the trend is for it to "retreat within its noble boundaries" by becoming a purely consultative body.
The Athenaeum will also provide some innovative approaches to tackling the industry - research gap. For instance, Hungarian engineers needed in high technology industries such as microelectronics are thought to lack training in basic subjects so it is planned to offer high level courses in physics-related topics to several tens of engineers from the Technical University and elsewhere after their threeyear basic course.

All in all, there is a will in Hungary to support basic and long-term physics research and to develop the required skills as "science provides the essential background to industry". In the meantime, the urgent need is to reduce bureaucracy, and the great danger is that people may become depressed if the expected miracles do not materialize.

P. G. Boswell

\section{Extended Shutdown for ILL Neutron Source}

The Institut von Laue-Langevin in Grenoble with its High Flux Reactor neutron source. Shown in the foreground is the building that is being constructed to house the storage ring of the European Synchrotron Radiation Facility (ESRF).

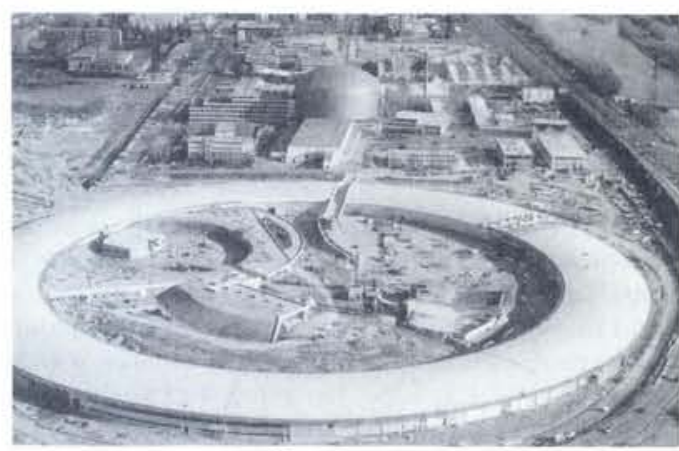

The Institut Laue-Langevin (ILL) in Grenoble, France, has announced that its $55 \mathrm{MW}$ High Flux Reactor neutron source for structure studies would not be restarted as scheduled at the end of a routine inspection that began on 30 March 1991 and would normally have lasted a few days. This was because elongated, radially orientated "traces inhabituelles" (literally, unusual traces) had been observed on the upper surface of the upper baffle of a two-baffle assembly located near the bottom of the reactor vessel. This 2.5 metre diameter, $6 \mathrm{~mm}$ thick aluminium alloy baffle plate has 6000 holes of $9.5 \mathrm{~mm}$ diameter that serve to quieten circulating heavy water coolant which is pumped under pressure into the bottom of the vessel. The traces were found on April 5 during a remote examination by video camera of the interior of the vessel and its components: a detailed on-going inspection has confirmed the observations.

The ILL, whose function is to make available a range of instruments for structure studies to the scientific community, charges its Reactor Division with supplying neutrons. Dr. E. Bauer, the Head, has indicated that the ILL Directors will propose to the ILL Steering Committee, comprising representatives of the four national Associate Members and responsible for establishing the general rules for managing the Institute, that the baffle assembly be replaced. This intervention will take up to about one year to prepare and a similar period to carry out.

Operation of the ILL's reactor is the same as for any other French reactor and is "fully embedded" in the French nuclear safety system reporting to a Minister. The observations were reported immediately to the relevant authority and it is the Minister who will authorize the ILL's proposed intervention plan. Safety procedures had been recently reevaluated in the investigation process which followed the discovery, in early 1990, that the HFR had been operating above its rated power for some time owing to erroneous calibration.

The inevitably extended shutdown will clearly have important consequences for the 1500 users of the ILL's 30 instruments who made 2400 individual visits in 1990 , especially since they had to adjust to the 1990 shutdown which reduced the number of 44 day operating cycles from 6 to 4.5 only a year after the ILL had boosted the annual beam time from roughly 220 hours to 262 hours in 1989 to cope with excess demand. The future of the 99 th beam cycle, that was postponed soon after the traces were observed and had been tentatively scheduled to start on 18 June, is undecided. 